\title{
(-)-Epicatechin Suppresses Angiotensin II-induced Cardiac Hypertrophy via the Activation of the SP1/SIRT1 Signaling Pathway
}

\author{
Zeng-xiang Donga,c Lin Wan ${ }^{a}$ Ren-jun Wang ${ }^{b}$ Yuan-qi Shia Guang-zhong Liu ${ }^{a}$ \\ Si-jia Zheng ${ }^{c}$ Hui-ling Hou ${ }^{d}$ Wei Han ${ }^{a}$ Xin Haic \\ aDepartment of Cardiology, the First Affiliated Hospital of Harbin Medical University, Harbin, \\ ${ }^{b}$ Department of Biotechnology, School of Life Science, Jilin Normal University, Siping, 'Department of \\ Clinical Pharmacy, the First Affiliated Hospital of Harbin Medical University, Harbin, dDepartment of \\ Pharmacy, Qiqihar Medical University, Qiqihar, China
}

\section{Key Words}

Epicatechin • Angiotensin II • Cardiac hypertrophy • SP1 • SIRT1

\begin{abstract}
Background/Aims: Flavonol (-)-epicatechin (EPI) is present in high amounts in cocoa and tea products, and has been shown to exert beneficial effects on the cardiovascular system. However, the precise mechanism of EPI on cardiomyocyte hypertrophy has not yet been determined. In this study, we examined whether EPI could inhibit cardiac hypertrophy. Methods: We utilised cultured neonatal mouse cardiomyocytes and mice for immunofluorescence, immunochemistry, qRT-PCR, and western blot analyses. Results: $1 \mu \mathrm{M}$ EPI significantly inhibited $1 \mu \mathrm{M}$ angiotensin II (Ang II)-induced increase of cardiomyocyte size, as well as the mRNA and protein levels of ANP, BNP and $\beta-M H C$ in vitro. The effects of EPI were accompanied with an up-regulation of SP1 and SIRT1, and were abolished by SP1 inhibition. Up-regulation of SP1 could block Ang II-induced increase in cardiomyocyte size, as well as the mRNA and protein levels of ANP, BNP and $\beta-\mathrm{MHC}$, and increase the protein levels of SIRT1 in vitro. Moreover, $1 \mathrm{mg} / \mathrm{kg}$ body weight/ day EPI significantly inhibited mouse cardiac hypertrophy induced by Ang II, which could be eliminated by SP1 inhibition in vivo. Conclusion: Our data indicated that EPI inhibited AngIIinduced cardiac hypertrophy by activating the SP1/SIRT1 signaling pathway.
\end{abstract}

(C) 2017 The Author(s)

Published by S. Karger AG, Basel

\section{Introduction}

Cardiac hypertrophy is a major consequence of the heart overload or pathophysiological injury [1]. The typical features of cardiac hypertrophy are reactivation of fetal cardiac genes

Z.-x. Dong and L. Wan contributed equally to this article. 
and increased heart mass and associated changes in the shape of the left ventricle. Cardiac hypertrophy initially occurs as a compensatory response, and it can result in heart failure and arrhythmias, which are the leading cause of sudden death [2-4]. Due to the grave outcome of cardiac hypertrophy, many studies have attempted to determine the underlying mechanisms of cardiac hypertrophy and identify therapeutic strategies to inhibit it. Silent information regulator 1 (SIRT1), a NAD-dependent histone deacetylase, belongs to the mammalian sirtuin family. SIRT1 plays a vital role in many pathophysiological processes, such as apoptosis, autophagy, proliferation, cell cycle, inflammation, stress resistance, and metabolism [5-7]. Various studies have demonstrated that the role of SIRT1 in cardiac hypertrophy is complex [8]. A recent study revealed that activation of Sirt1 could inhibit cardiac hypertrophy [9].

Many recent studies have shown that intake of flavonoid-rich foods, such as cocoa and tea, can prevent cardiovascular disease (CVD). These studies showed that the consumption of chocolate results in approximately a $40 \%$ reduction in the risk of CVD [10]. The consumption of tea can also reduce the risk of stroke and diabetes by approximately $20 \%$ [11] and $15 \%$ [12], respectively. Epicatechin (EPI) is considered an important factor that may be responsible for the beneficial effects of these flavanol-rich foods $[13,14]$. Pharmacological studies have found that EPI exhibits protective effects on oxidative stress injury, myocardial ischemia reperfusion injury and permanent coronary occlusion [15-17]. EPI treatment also improved mitochondrial structure in enhanced cardiac and/or SkM muscle function in patients with heart failure. Moreover, EPI increased the protein expression of SIRT1 [18]. Taken together, these results indicate a beneficial role for EPI in cardioprotective function and specifically in the protection of heart failure. Moreover, a previous study reported that EPI could significantly decrease the level of pathological cardiac hypertrophy markers atrial natriuretic peptide (ANP) and brain natriuretic peptide (BNP) in the hearts of normal mice [19]. However, it is unknown whether EPI has a direct effect on cardiac hypertrophy and the mechanism underlying its antihypertrophic role remains unclear.

Thus, the aim of the present study was to determine the role of EPI in Ang II-induced cardiac hypertrophy. In this study, we evaluated the antihypertrophic effects of EPI and disclosed the underlying mechanisms, involving regulation of the SP1/SIRT1 signaling pathway in cardiac hypertrophy in vitro and in vivo.

\section{Materials and Methods}

\section{Chemicals and Animal Care}

$(-)$-Epicatechin (purity $\geq 98 \%$ ) and all other chemicals used in this study were purchased from SigmaAldrich (St. Louis, MO, USA). EPI was dissolved in PBS ( $\mathrm{pH} 7.4$ ). All animal experimental procedures were approved by the ethical committee of Harbin Medical University, China and were performed according to the published NIH guidelines for animal research (NIH Publication No. N01-OD-4-2139, $8^{\text {th }}$ edition, 2011).

Isolation of Neonatal Cardiomyocyte and Cell Models for Hypertrophy

Neonatal mouse ventricular myocytes were isolated and cultured from the ventricles of 1-to-3-dayold C57BL/6 mice. Mouse hearts were removed aseptically and large vessels and atria were discarded. The ventricles were washed and cut into small pieces in serum-free DMEM (Dulbecco's modified Eagle's medium), and then digested in $0.25 \%$ trypsin in a $\mathrm{CO}_{2}$ incubator at $37^{\circ} \mathrm{C}$ for $15 \mathrm{~min}$. To enrich for cardiomyocytes and to deplete nonmyocytes, the cells were centrifuged and cultured in DMEM for $2 \mathrm{~h}$, allowing the attachment of nonmyocytes. After the purification process, cardiomyocytes were resuspended and cultured in DMEM supplemented with $15 \%$ fetal bovine serum (FBS). The culture medium was renewed after $48 \mathrm{~h}$ and cardiomyocytes were further cultured for $24 \mathrm{~h}$. Next, the culture medium was changed to serum-free DMEM and the cardiomyocytes were pretreated with $1 \mu$ M EPI (Sigma, St. Louis, MO, USA) or phosphate buffer saline (PBS) for $1 \mathrm{~h}$ and then stimulated with $1 \mu \mathrm{M}$ Ang II (Sigma, St. Louis, MO, USA) for $48 \mathrm{~h}$. 


\section{Cellular Physiology Cell Physiol Biochem 2017;41:2004-2015

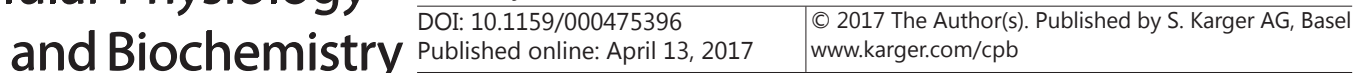 \\ Dong et al.: Epicatechin Inhibits Cardiac Hypertrophy}

Synthesis of SP1 Decoy and Transfection

The pN3-SP1 FL vector was provided by Dr. Guntram Suske (Institut fur Molekularbiologie und Tumourforschung, Philipps-Universitat Marburg, Marburg, Germany). The Sp1 decoy (5'-ATTACCGGGCGGGCGGGCTAC-3') and its antisense oligonucleotides (5'-GTAGCCCGCCCGCCCGGTAAT-3') were synthesised by Sangon Inc. (Shanghai, China). The Sp1 cDNA and Sp1 decoy were delivered into the neonatal mouse ventricular myocytes using Lipofectamine 2000 (Invitrogen, Carlsbad, CA, USA). After incubation for $24 \mathrm{~h}$, the cardiomyocytes were prepared for the following stimulation experiment.

\section{Animal Experiments}

Eight-to-10-week-old C57BL/6 mice (23-27 g body weight) were supplied by the Medical Experimental Animal Center of Harbin Medical University, China. The mice were housed under standard animal room conditions (temperature $25 \pm 1{ }^{\circ} \mathrm{C}$; humidity 50-60\%) and provided with food and water ad libitum throughout the study. The animals were randomly distributed into four groups as follows: control group (control, $n=6$ ), Ang II-stimulation group (Ang II, $n=6$ ), Ang II stimulation with EPI pre-treatment group (Ang II + EPI, n=6), and Ang II stimulation with EPI + mithramycin (MTM) pre-treatment group (Ang II + EPI + MTM, n=6). One week before Ang II-stimulation, the mice received 7 days pre-treatment with $0.9 \%$ salt solution (control group) or $1 \mathrm{mg} / \mathrm{kg} /$ day EPI (or/and $0.1 \mathrm{mg} / \mathrm{kg} /$ day MTM of body weight by intraperitoneal injection) by oral gavage as previously described [20]. After 7 days pre-treatment with a salt solution or EPI, the model of cardiac hypertrophy was established by administration of Ang II at $1 \mathrm{mg} /$ kg/day for 14 days using osmotic mini-pumps (1007D; Alza Corp., Mountain View, CA, USA), which were implanted subcutaneously in mice. After drug administration, the mice received food and water ad libitum and their hearts were collected after 14 days under anaesthesia. The heart weight/body weight (HW/BW) ratio was calculated and the heart samples were frozen and stored in liquid nitrogen.

\section{Measurement of the Cell Surface Area}

After Ang II, EPI and transfection stimulation, the cardiomyocytes were plated onto chamber slides, fixed with $4 \%$ paraformaldehyde for 20 min and permeabilised with $0.1 \%$ Triton X-100 in PBS, followed by blocking with $3 \%$ BSA for $1 \mathrm{~h}$ at room temperature. The cardiomyocytes were incubated with monoclonal antibody against sarcomeric $\alpha$-actinin (1:800 dilution, Sigma, St. Louis, MO, USA) at $4{ }^{\circ} \mathrm{C}$ overnight. Nuclear staining was performed by incubating with 4', 6-diamidino-2- phenylindole (DAPI, Sigma, St. Louis, MO, USA) at room temperature for $10 \mathrm{~min}$. Cardiomyocytes were imaged at 200× magnification using a Carl Zeiss Axio VertA1 microscope (Carl Zeiss Microimaging, Thornwood, NY, USA). The cardiomyocyte surface was determined using ImagePro Plus software (version 6.0, Media Cybernetics) and the relative surface area was read with arbitrary units (the number of pixels) to evaluate hypertrophy. The cell surface area in control cells was expressed as 1.

\section{Quantitative Reverse Transcription-PCR ( $q R T-P C R$ )}

Quantitative analysis of atrial natriuretic peptide (ANP), brain natriuretic peptide (BNP) and $\beta$-myosin heavy chain ( $\beta$-MHC) mRNA expression in cardiomyocytes and cardiac tissues was determined using realtime polymerase chain reaction. Total RNA was extracted from cardiomyocytes and cardiac tissues using Trizol reagent (Invitrogen, Carlsbad, CA, USA) according to the manufacturer's protocols. Next, $0.5 \mu \mathrm{g}$ of total RNA was reverse transcribed using the High-Capacity cDNA Reverse Transcription Kit (Applied Biosystems, Foster City, CA, USA) to obtain cDNA. The SYBR Green PCR Master Mix Kit (Applied Biosystems, Foster City, CA, USA) was used in qRT-PCR to quantify the RNA levels of the hypertrophic markers such as ANP, BNP and $\beta$-MHC in cardiomyocytes, with GAPDH as an internal control. The qRT-PCR was performed on 7500 FAST Real-Time PCR System (Applied Biosystems, USA) for 40 cycles. The sequences of primers used for amplification were: ANP, 5'-CTCCGATAGATCTGCCCTCTTGAA-3' and 5'-GGTACCGGAA GCTGTTGCAGCCTA-3'; BNP, 5'-TGATTCTGCTCCTGCTTTTC-3' and 5'-GT GGATTGTTCTGGAGACTG-3'; $\beta$-MHC, 5'-CAGCAGCCCAGTACCTCCGA-3' and 5'-TGTCATCAGGCACGAAGCAC-3'; GAPDH, 5'-AAGAATGGTGAAGC AGGC-3' and 5' - TCCACCACCAGTTGCTGTA-3'. Data were analysed using the comparative Ct ( $\Delta \Delta \mathrm{Ct}) \operatorname{method}$ for relative quantification. In this study, $\Delta \mathrm{Ct}$ was calculated as Ct (detected mRNA)-Ct (GAPDH) and $\Delta \Delta \mathrm{Ct}$ was calculated as $\Delta \mathrm{Ct}$ (drug treated) - $\Delta \mathrm{Ct}$ (control), where the control is the group treated with non-drugs. The relative value was obtained by $2^{-\Delta \Delta \mathrm{CT}}$.

\section{KARGER}




\section{Cellular Physiology Cell Physiol Biochem 2017;41:2004-2015

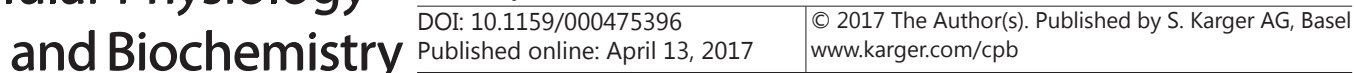 \\ Dong et al.: Epicatechin Inhibits Cardiac Hypertrophy}

Western Blotting Analysis

Total protein was extracted from cultured neonatal cardiomyocytes and mouse hearts. The protein concentrations were determined with a BCA protein assay kit using bovine serum albumin (BSA) as the standard. Next, $150 \mu \mathrm{g}$ of protein samples were separated by $15 \%$ acrylamide denaturing gels (SDS-PAGE) and then transferred onto PVDF transfer membrane (Millipore, Bedford, MA, USA). Membranes were blocked with $5 \%$ non-fat milk for $1 \mathrm{~h}$ at room temperature and then incubated with anti-SP1, anti-SIRT1 (1:1000 dilution, Cell Signaling Technology, Danvers, MA, USA), anti-ANP (1:200 dilution, Abcam, Cambridge, MA, USA), anti-BNP (1:200 dilution, Abcam, Cambridge, MA, USA), anti- $\beta$-MHC (1:1000 dilution, Cell Signaling Technology, Danvers, MA, USA), and anti-GADPH (1:5000 dilution; Cell Signaling Technology, Danvers, MA, USA) antibodies overnight at $4{ }^{\circ} \mathrm{C}$. Following incubation with the primary antibodies and after washing, the membranes were incubated with secondary antibody (1:2000 dilution, Alexa Fluor ${ }^{\circledR} 700$ goat anti-

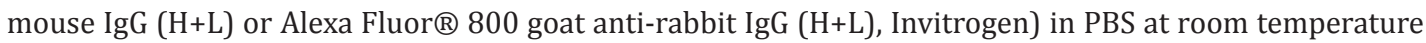
for $1 \mathrm{~h}$. Finally, the western blot bands were visualised using the Odyssey Infrared Imaging System (LI-COR Biosciences, Lincoln, NE, USA) and quantified using Odyssey v 1.2 software (LI-COR Biosciences, Lincoln, $\mathrm{NE}$, USA) by measuring the band intensity (area $\times$ OD) in each group and normalising against GAPDH as an internal control. Each western blot experiment was repeated six times.

\section{Histology}

Following fixation in formalin (10\%), heart tissues specimens were embedded in paraffin. Crosssections along the minor axis were obtained using a microtome and then stained with Mayer's Haematoxylin and Eosin. Cardiomyocyte hypertrophy was quantified by measuring the diameter of 100 randomly sectioned (transverse) cardiomyocytes per microscopic field. Sections were imaged at 20× magnification using a Carl Zeiss microscope (Carl Zeiss Microimaging, Thornwood, NY, USA).

\section{Statistical Analysis}

All statistical analyses were performed using Prism (Graphpad) software. The data were presented as the mean \pm standard error of mean (SEM) and analysed using SPSS 13.0 software. Two independent Student's $t$-tests and one-way ANOVA were used for difference comparisons. All statistical significance was two-tailed and the significance level was established at 0.05 . A value of $P<0.05$ was considered to be statistically significant.

\section{Results}

EPI Attenuates Ang II-Induced Cardiac Hypertrophy in Neonatal Mouse Cardiomyocytes

Consistent with findings obtained in previous research studies, cardiac hypertrophy could be induced by Ang II [21-23]. To investigate whether EPI could attenuate Ang IIinduced cardiac hypertrophy, neonatal mouse cardiomyocytes were treated with EPI (1 $\mu \mathrm{mol} / \mathrm{L})$ and/or Ang II $(1 \mu \mathrm{mol} / \mathrm{L})$ as described in the methods section. We observed that Ang II markedly increased the cell area of cardiomyocytes $(2.81 \pm 0.09$ in Ang II group vs. $0.95 \pm 0.05$ in control group, $P<0.01$ ) as assessed using cardiomyocyte immunofluorescence and cell surface area analysis, and EPI could reverse the effects of Ang II (1.16 \pm 0.16 in cotreatment of EPI + Ang II group vs. $2.81 \pm 0.09$ in Ang II group, $P<0.05$ ) (Fig. 1 A and B).

To further investigate the effect of EPI on cardiac hypertrophy, we examined the effect of EPI on the markers of cardiac hypertrophy. A feature of cardiac hypertrophy is reflected by increased protein contents such as atrial natriuretic peptide (ANP), brain natriuretic peptide (BNP) and $\beta$-myosin heavy chain ( $\beta$-MHC). Thus, we firstly investigated the effects of $1 \mu \mathrm{M}$ Ang II on the expressed of these proteins in cardiomyocytes. Ang II induced an increase in ANP, BNP and $\beta$-MHC mRNA expression ( $P<0.01$ vs. control group) (Fig. $2 \mathrm{~A}-\mathrm{C})$. In contrast, $1 \mu \mathrm{M}$ EPI significantly attenuated Ang II-induced ANP, BNP and $\beta$-MHC expression $(P<0.05$ vs. Ang II group). As shown in Fig. 2 D-F, Ang II increased the protein expression of ANP, BNP and $\beta$-MHC in cardiomyocytes $(P<0.01$ vs. control group). These changes were inhibited by $1 \mu \mathrm{M}$ EPI in the culture medium $(P<0.05$ vs. Ang II group). Taken together, these results 
Fig. 1. Effect of EPI on cardiac hypertrophy induced by Ang II in vitro. (A) The cell areas were detected by an immunofluorescence assay in neonatal mouse cardiomyocytes stained with DAPI and $\alpha$-actinin (Original magnification, 200x) exposed to control (PBS), $1 \mu \mathrm{M}$ Ang II, and $1 \mu \mathrm{M}$ Ang II $+1 \mu \mathrm{M}$ EPI for 48h. (B) Quantification of cell surface areas using immunofluorescence and cell surface area analysis, $n=10$ independent experiments for each group. Data are expressed as the mean \pm SEM. ${ }^{* *} P<0.01$ vs. control group; $\# P<0.05$ vs. Ang II group.
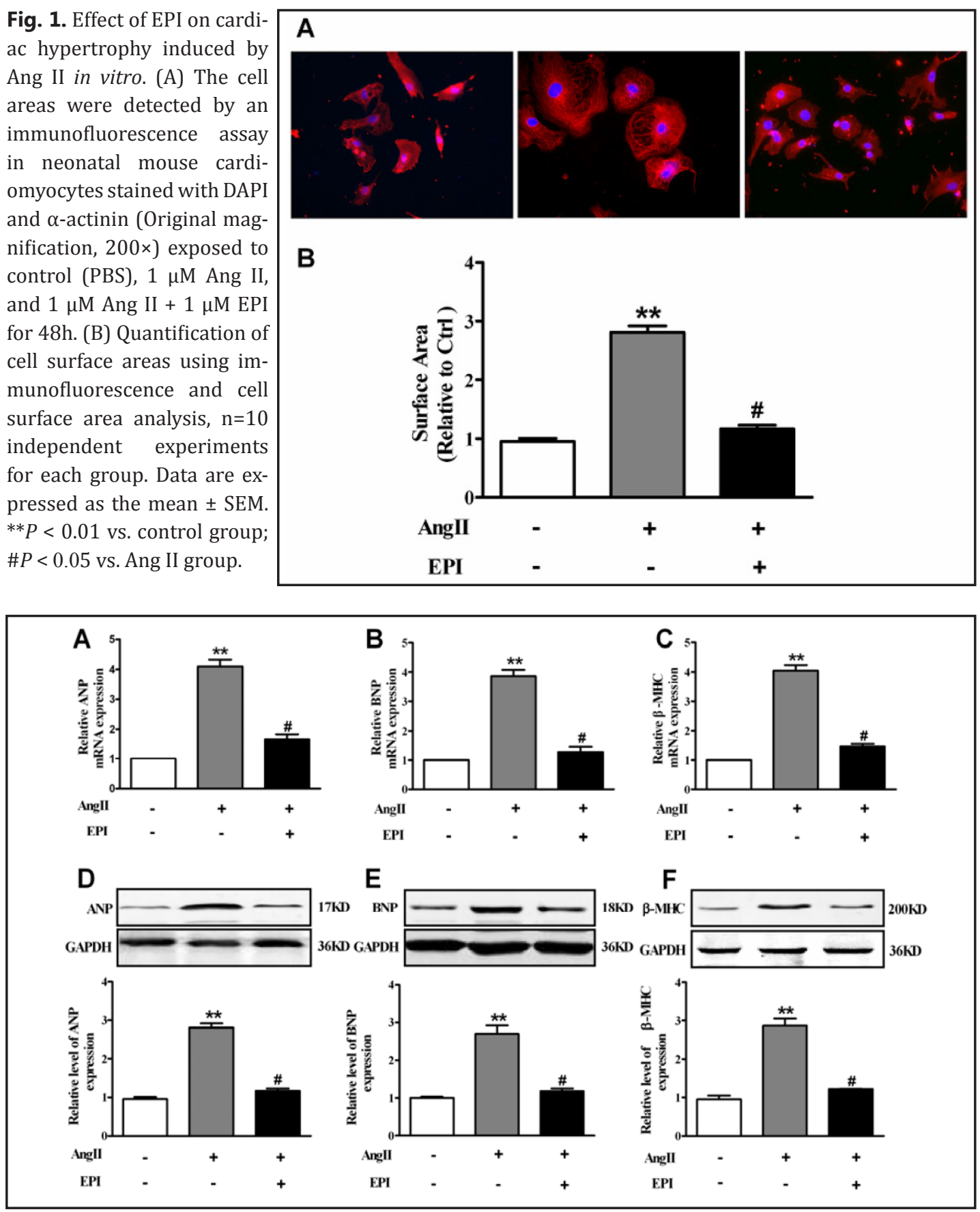

Fig. 2. Effect of EPI on markers of Ang II-induced cardiac hypertrophy in vitro. (A-C) The mRNA expression level of ANP, BNP and $\beta$-MHC by qRT-PCR analysis in cardiomyocytes exposed to control (PBS), $1 \mu$ M Ang II, and $1 \mu \mathrm{M}$ Ang II $+1 \mu \mathrm{M}$ EPI. (D-F) Protein levels of ANP, BNP and $\beta$-MHC. $n=6$ independent experiments for each group. Data are expressed as the mean \pm SEM. ${ }^{* *} P<0.01$ vs. control group; $\# P<0.05$ vs. Ang II group.

indicated that Ang II-Induced hypertrophy in cardiomyocytes could be attenuated by EPI in vitro.

Effect of EPI on the SP1/SIRT1 Signaling Pathway

A previous study reported that activation of SIRT1 could suppress Ang II type I receptor expression in vivo and in vitro [24]. Thus, we examined the effect of EPI on the expression 
A

A
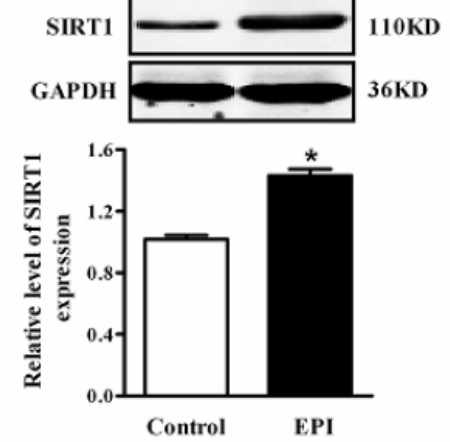

C

B
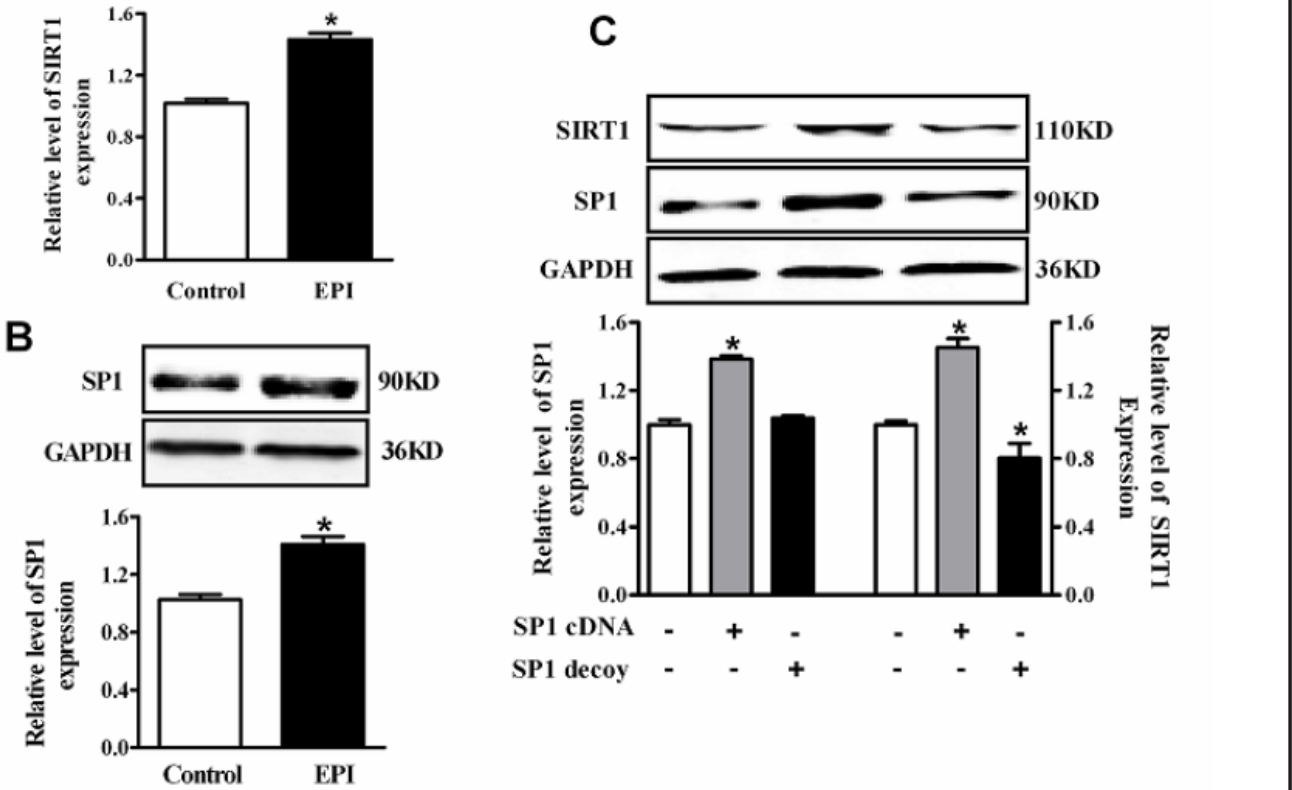

Fig. 3. Effect of EPI on expression of SIRT1 and SP1. (A) Protein levels of SIRT1 as assessed using western blotting analysis in neonatal mouse cardiomyocytes exposed to control (PBS) and $1 \mu \mathrm{M}$ EPI for $48 \mathrm{~h}$. (B) Protein levels of SP1 as assessed using western blotting analysis in neonatal mouse cardiomyocytes exposed to control (PBS) and $1 \mu \mathrm{M}$ EPI for $48 \mathrm{~h}$. (C) Protein levels of SIRT1 and SP1 as assessed using western blotting analysis in neonatal mouse cardiomyocytes exposed to control, transfection of SP1 cDNA and SP1 decoy. n=6 independent experiments for each group. Data are expressed as the mean \pm SEM. ${ }^{*} P<0.05$ vs. control group.

of SIRT1. Cardiomyocytes were incubated with $1 \mu \mathrm{M}$ EPI for $48 \mathrm{~h}$, and the expression level of SIRT1 and SP1 was determined using western blotting analysis. The expression level of SIRT1 and SP1 were significantly increased by EPI treatment at $48 \mathrm{~h}$ compared with the control group (Fig. $3 \mathrm{~A}$ and $\mathrm{B}, P<0.05$ ). To determine the potential relationship between SP1 and SIRT1, we transiently expressed SP1 cDNA and SP1 decoy in cardiomyocytes for $48 \mathrm{~h}$, and performed western blotting analyses to examine the protein levels of SP1 and SIRT1 (Fig. 3C). These results showed that transiently expressed SP1 cDNA increased the expression of SP1 and SIRT1 protein ( $P<0.05$ vs. control group), and the SP1 decoy decreased the expression of SIRT1 protein ( $P<0.05$ vs. control group).

EPI Inhibits Ang II-Induced Cardiac Hypertrophy by Activating the SP1/SIRT1 Signaling Pathway

To confirm the effect of the SP1/SIRT1 signaling pathway on EPI inhibition of cardiac hypertrophy, we investigated the change in cardiomyocyte area induced by Ang II, EPI and SP1 decoy in vitro. As shown in Fig. 4A-B, we observed that Ang II markedly increased the cell area of cardiomyocytes (2.77 \pm 0.12 in Ang II group vs. $1.00 \pm 0.03$ in control group, $P<$ 0.01 ) using cardiomyocyte immunofluorescence and cell surface area analysis. In addition, EPI alleviated the hypertrophy of cardiomyocytes $(1.20 \pm 0.08$ in co-treatment of EPI + Ang II group vs. $2.77 \pm 0.12$ in Ang II group, $P<0.05)$, while the SP1 decoy reversed the effects of EPI on the change in cardiomyocytes area $(2.36 \pm 0.09$ in co-treatment of EPI + Ang II + SP1 decoy group vs. $1.20 \pm 0.08$ in co-treatment of EPI + Ang II group, $P<0.05$ ).

To further investigate the effect of the SP1/SIRT1 signaling pathway on EPI inhibition of cardiac hypertrophy, we examined the markers of cardiac hypertrophy. As shown in Fig. 
Fig. 4. Effect of SP1 on cardiac hypertrophy induced by AngII. (A) The cell areas were detected using an immunofluorescence assay in neonatal mouse cardiomyocytes stained with DAPI and $\alpha$-actinin (Original magnification, 200x) exposed to control (PBS), $1 \mu \mathrm{M}$ Ang II, $1 \mu \mathrm{M}$ Ang II $+1 \mu \mathrm{M}$ EPI, and 1 $\mu \mathrm{M}$ Ang II $+1 \mu \mathrm{M}$ EPI + SP1 decoy. (B) Quantification of cell surface areas using immunofluorescence and cell surface area analysis, $n=10$ independent experiments for each group. Data are expressed as the mean \pm SEM. ${ }^{* *} P<0.01$ vs. control group; $\# P<0.05$ vs. Ang II group; \& $P<0.05$ vs. Ang II + EPI group.
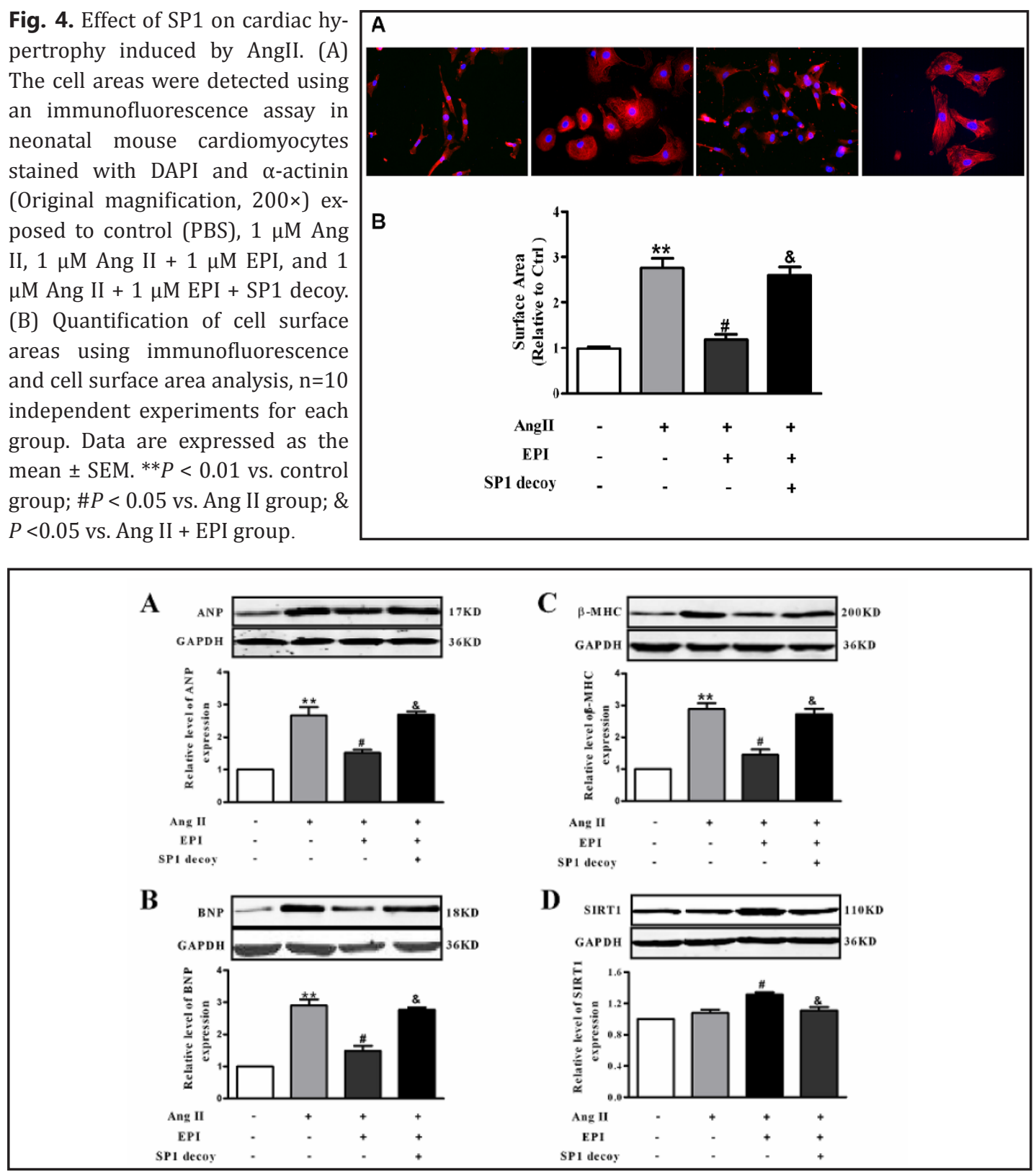

Fig. 5. Effect of SP1 on markers of Ang II-induced cardiac hypertrophy. (A-C) The protein levels of ANP, $\mathrm{BNP}$ and $\beta$-MHC as assessed using western blotting analysis in neonatal mouse cardiomyocytes exposed to control (PBS), $1 \mu \mathrm{M}$ Ang II, $1 \mu \mathrm{M}$ Ang II $+1 \mu \mathrm{M}$ EPI, $1 \mu \mathrm{M}$ Ang II + $1 \mu \mathrm{M}$ EPI + transfection of SP1 decoy. (D) Protein levels of SIRT1 in neonatal mouse cardiomyocytes exposed to control (PBS), $1 \mu \mathrm{M}$ Ang II, $1 \mu \mathrm{M}$ Ang II $+1 \mu \mathrm{M}$ EPI, $1 \mu \mathrm{M}$ Ang II $+1 \mu \mathrm{M}$ EPI + transfection of SP1 decoy. $\mathrm{n}=6$ independent experiments for each group. Data are expressed as the mean \pm SEM. ${ }^{* *} P<0.01$ vs. control group; $\# P<0.05$ vs. Ang II group; \& $P<$ 0.05 vs. Ang II + EPI group.

5A-C, Ang II induced increases in ANP, BNP and $\beta$-MHC protein expression in neonatal mouse cardiomyocytes $(P<0.01$ vs. control group). In contrast, EPI significantly attenuated Ang II-induced ANP, BNP and $\beta$-MHC expression $(P<0.05$ vs. Ang II group). Moreover, the SP1 decoy reversed the effects of EPI on the changes in ANP, BNP and $\beta$-MHC expression $(P<0.05$ vs. Ang II + EPI group). As shown in Fig. 5D, EPI significantly increased SIRT1 expression ( $P$ $<0.05$ vs. Ang II group). Furthermore, SP1 decoy blocked the effects of EPI on the changes in SIRT1 expression. Taken together, these results indicated that Ang II-Induced hypertrophy 
A

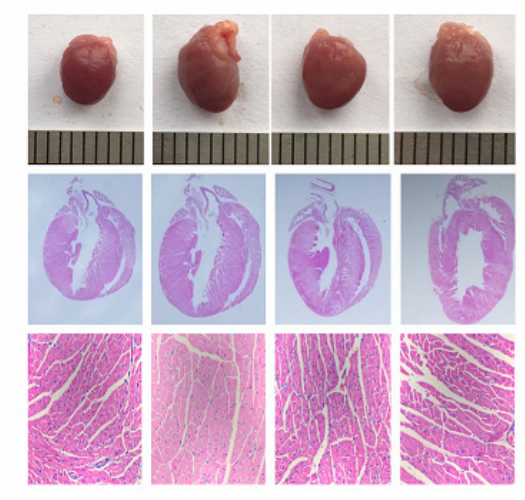

B

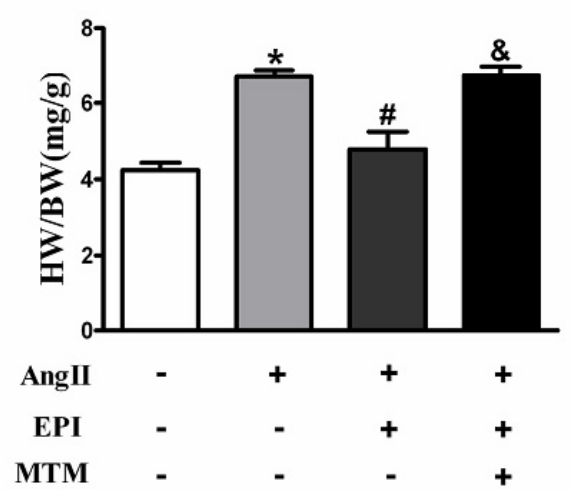

Fig. 6. Effect of EPI on cardiac hypertrophy induced by Ang II in vivo. (A) Gross hearts and heart sections stained with haematoxylin and eosin of mice treated with control (PBS), $1 \mathrm{mg} / \mathrm{kg}$ body weight $/$ day Ang II, 1 $\mathrm{mg} / \mathrm{kg}$ body weight /day Ang II $+1 \mathrm{mg} / \mathrm{kg}$ body weight /day EPI, and $1 \mathrm{mg} / \mathrm{kg}$ body weight /day Ang II +1 $\mathrm{mg} / \mathrm{kg}$ body weight /day EPI $+0.1 \mathrm{mg} / \mathrm{kg}$ body weight /day MTM for $14 \mathrm{~d}$. (B) Heart weight to body weight ratios (HW/BW) in different groups. $n=6$ independent experiments for each group. Data are expressed as the mean \pm SEM. $* P<0.05$ vs. control; $\# P<0.05$ vs. Ang II group; $\& P<0.05$ vs. Ang II + EPI group.

in cardiomyocytes could be attenuated by EPI via activation of the SP1/SIRT1 signaling pathway in vitro.

EPI Significantly Inhibits Mouse Cardiac Hypertrophy Induced by Ang II in Vivo

To further determine the antihypertrophic role of EPI in Ang II-induced cardiac hypertrophy, we investigated the beneficial effects of EPI in vivo. As shown in Fig. 6A-B, the ratio of heart weight $(\mathrm{HW})$ to body weight (BW) was increased in mice with Ang II treatment $(P<0.05$ vs. control group), which was successfully inhibited by EPI pre-treatment $(P<$ 0.05 vs. Ang II group). Moreover, mithramycin (MTM), a well-known SP1-specific inhibitor, attenuated the effect of EPI in Ang II-induced cardiac hypertrophy $(P<0.05$ vs. Ang II + EPI group). H\&E staining of gross heart tissue confirmed the protective effect of EPI against cardiac hypertrophy. As demonstrated in Fig. 6 A-B, cardiomyocytes exhibited compactly arranged fibres with no intercellular space under the light microscopy in the control group. In contrast, cardiomyocytes were hypertrophic and cardiac muscle fibres were severely ruptured in the Ang II group. This condition was reversed after EPI treatment.

Furthermore, the protein expression level of ANP, BNP and $\beta$-MHC in mouse heart was examined after treatment with the drugs for two weeks. As shown in Fig. 7A-F, Ang II induced increases in ANP, BNP and $\beta$-MHC mRNA and protein expression $(P<0.01$ vs. control group). In contrast, EPI significantly decreased Ang II-induced ANP, BNP and MHC mRNA and protein expression $(P<0.05$ vs. Ang II group). Moreover, MTM attenuated the role of EPI in Ang II-induced ANP, BNP and MHC mRNA and protein expression $(P<0.05$ vs. Ang II + EPI co-treatment group). Taken together, these results revealed that EPI treatment exerted antihypertrophic function via SP1 in vivo.

\section{Discussion}

In the present study, we demonstrated that EPI inhibited cardiac hypertrophy induced by Ang II in vitro and vivo. Furthermore, our results indicated that the antihypertrophic effect of EPI was mediated through activation of the SP1/SIRT1 signaling pathway. A previous study found that cardiac hypertrophy is both an intermediate step and a determinant of heart failure. This is of important significance to the discovery of cellular and molecular 

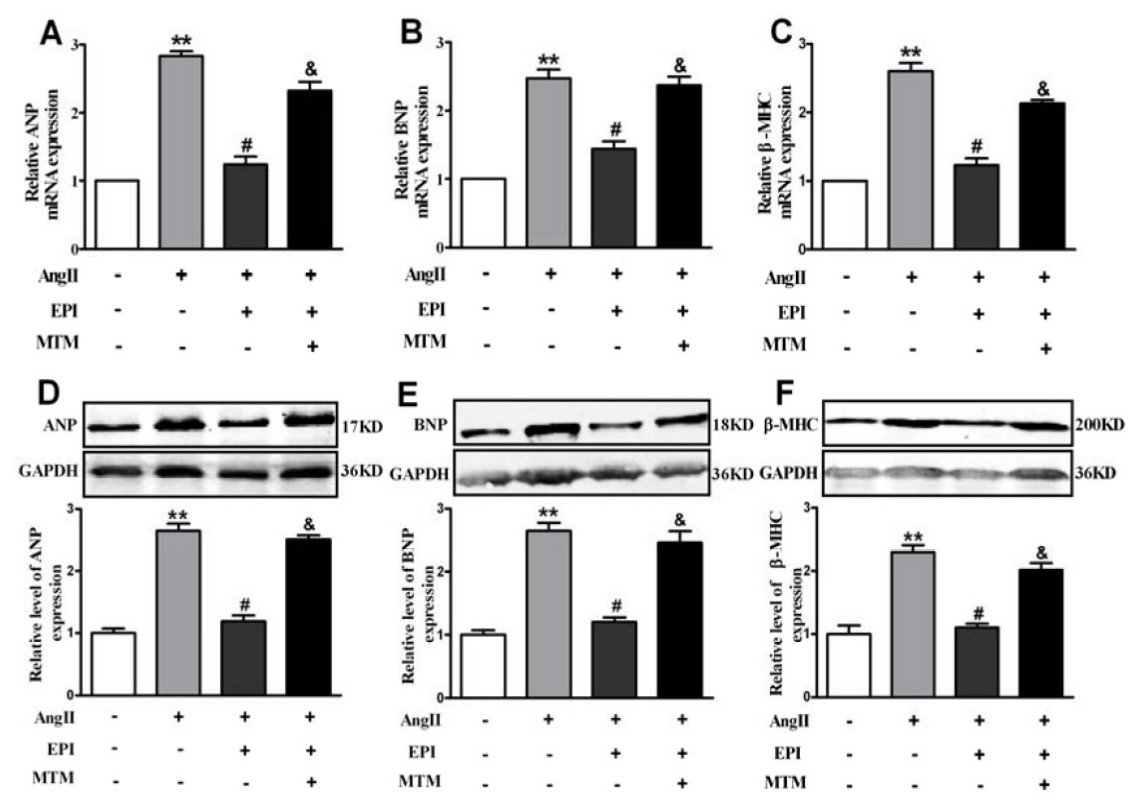

Fig. 7. Effect of EPI on markers of Ang II-induced mouse cardiac hypertrophy in vivo. (A-C) The mRNA expression level of ANP, BNP and $\beta$-MHC by qRT-PCR analysis in the hearts of mice treated with control (PBS), $1 \mathrm{mg} / \mathrm{kg}$ body weight /day Ang II, $1 \mathrm{mg} / \mathrm{kg}$ body weight /day Ang II + $1 \mathrm{mg} / \mathrm{kg}$ body weight /day EPI, and $1 \mathrm{mg} / \mathrm{kg}$ body weight /day Ang II $+1 \mathrm{mg} / \mathrm{kg}$ body weight /day EPI + $0.1 \mathrm{mg} / \mathrm{kg}$ body weight /day MTM for 14 d. (D-F) Protein levels of ANP, BNP and $\beta$-MHC. $n=6$ independent experiments for each group. Data are expressed as the mean \pm SEM. ${ }^{* *} P<0.01$ vs. control group; $\# P<0.05$ vs. Ang II group; $\& P<0.05$ vs. Ang II + EPI group.

mechanisms as well as the signaling pathways underlying hypertrophic remodelling and the identification of potential therapeutic approaches for the treatment of heart failure.

Flavanols are plant-derived nutrients that are found in many foods, such as vegetables, fruits, tea and cocoa. A clinical trial in patients has shown that high dietary intake of flavanols enhances memory performance and neural function in the dentate gyrus of the hippocampus, a region critical for learning and memory [25]. Evidence from dietary intervention studies shows that the intake of flavanols can be beneficial for cardiovascular function. Flavanolrich chocolate acutely improved arterial function and working memory performance counteracting the effects of sleep deprivation in healthy individuals. This performance may be due to the effects of flavonoids on blood pressure and peripheral and central blood flow $[26,27]$. The beneficial effects of flavanols also include improved endothelial function, antiinflammatory potency, inhibition of platelet activation, and increased vasodilatory capacity [28]. EPI is the most physiologically potent compound, and primarily accounts for the biological effects of flavanols [13]. It has been reported that EPI can reduce the mortality of CVD [29]. The protective effect of EPI may occur via a reduction in oxidative stress, and improvement of mitochondrial structure and function [15-17]. Previous studies have also revealed that EPI-rich cocoa treatment improved mitochondrial structure and enhanced cardiac and/or SkM muscle function in patients with heart failure [18]. Furthermore, some studies have indicated that the epicatechin conjugate (EGCG) can alleviate cardiomyocyte hypertrophy [30-32]. Here we examined the effects of EPI on cardiac hypertrophy. In the present study, we observed that EPI could suppress the enlargement of cardiomyocytes induced by Ang II in vitro. In addition, we found that EPI significantly decreased Ang IIinduced ANP, BNP and $\beta$-MHC expression, which are considered molecular markers of cardiomyocyte hypertrophy. Taken together, these results indicated that EPI can prevent Ang II-induced hypertrophy.

\section{KARGER}


How does EPI lead to antihypertrophy? Many studies have indicated that Ang II exerts direct effects on myocardial cells, including cardiomyocyte growth, accumulation of extracellular matrix and hypertrophy [33-35]. The prohypertrophic effect of Ang II was mediated by angiotensin type 1 receptor (AT1R), which was blocked to prevent cardiac hypertrophy [36]. A previous study in dicated thatSIRT1 down-regulated Ang II type 1 receptor expression in vascular smooth muscle cells [24]. Furthermore, Ang II slightly upregulated the expression of SIRT1 in mouse heart. However, SIRT1 overexpression attenuated Ang IIinduced cardiac hypertrophy [37]. In our current study, we found that the level of SIRT1 protein in cardiomyocyte was increased by EPI. Moreover, EPI could increase the protein expression of SP1, which was consistent with findings obtained in a previous study on the effect of 3-methyl-epicatechin on SP1 [38]. The transcription factor SP1 belongs to a member of the SP/KLF family, which acts as a target gene transcriptional activator or repressor [39]. A previous study found that SP1 bound to the SIRT1 gene promoter and enhanced its transcriptional activity [40]. In our study, the protein levels of SIRT1 were upregulated in parallel with an increase in SP1 protein expression. These results suggest that SIRT1 may function as an important trigger for antihypertrophy of EPI via SP1. To confirm the effect of the SP1/SIRT1 signaling pathway on EPI inhibition of cardiac hypertrophy, we investigated the change in cardiomyocytes area, the expression of markers of cardiac hypertrophy and SIRT1 expression induced by EPI or/and SP1 decoy in vitro. Our results demonstrated that EPI activated SP1 and SIRT1, which is essential for the inhibition of cardiac hypertrophy.

This antihypertrophic effect and mechanism of EPI was further investigated in vivo. A previous study indicated that $1 \mathrm{mg} / \mathrm{kg}$ /day EPI of body weight by oral gavage for $10 \mathrm{~d}$ decreased infarct size, and reduced inflammation, reactive oxygen species generation and matrix metalloproteinase activity under conditions of ischemia-reperfusion [16]. Furthermore, $1 \mathrm{mg} / \mathrm{kg} /$ day EPI for $14 \mathrm{~d}$ could significantly decrease the levels of ANP and BNP in the hearts of normal mice [19]. On the basis of these results, we utilised this dose to study the protective effect of EPI on cardiac hypertrophy induced by Ang II. In the present study, we found that heart mass was increased, cardiomyocytes were hypertrophied and cardiac muscle fibres were severely ruptured in the Ang II group. In addition, markers of cardiac hypertrophy were increased. EPI could inhibit Ang II-induced hypertrophy in mice. These results were consistent with the cellular studies. Moreover, the effect was reversed after MTM treatment. Taken together, these results confirmed that EPI could inhibit Ang IIinduced cardiac hypertrophy by activating SP1 in vivo.

In conclusion, we found that EPI inhibited cardiac hypertrophy in vitro and in vivo. This study found that SP1/SIRT1 contributed to EPI-regulated cardio-protection. Thus, these findings provide evidence that EPI might become a therapeutic agent to reduce cardiac hypertrophy. Moreover, our findings may also explain the reason why EPI-rich foods have beneficial effects on heart failure.

\section{Acknowledgements}

This work was supported by the National Nature Science Foundation of China (81400250, 81470461, 81202527, and 81270251), Program for the Development of Science and Technology of Jilin Province (20130522002JH), the Science and Technology Research Project of Jilin Provincial Department of Education (2015212). China Postdoctoral Science Foundation funded project (2014M550201), Heilongjiang Provincial Government (LBH-Z13160).

\section{Disclosure Statement}

None declared. 


\section{Cellular Physiology Cell Physiol Biochem 2017;41:2004-2015

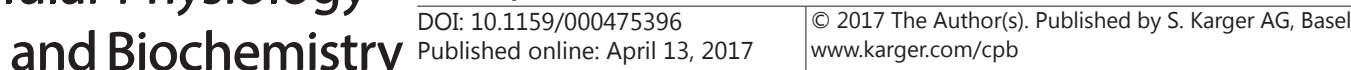

Dong et al.: Epicatechin Inhibits Cardiac Hypertrophy

\section{References}

1 Bell D, Campbell M, Wang X, Earle JA, Cosby SL, McDermott BJ: Adrenomedullin gene delivery is cardioprotective in a model of chronic nitric oxide deficiency combining pressure overload, oxidative stress and cardiomyocyte hypertrophy. Cell Physiol Biochem 2010;26:383-394.

2 Bisping E, Wakula P, Poteser M, Heinzel FR: Targeting cardiac hypertrophy: toward a causal heart failure therapy. J Cardiovasc Pharmacol 2014;64:293-305.

-3 Yang J, Chen YN, Xu ZX, Mou Y, Zheng LR: Alteration of RhoA Prenylation Ameliorates Cardiac and Vascular Remodeling in Spontaneously Hypertensive Rats. Cell Physiol Biochem 2016;39:229-241.

- 4 Kang YJ: Cardiac hypertrophy: a risk factor for QT-prolongation and cardiac sudden death. Toxicol Pathol 2006;34:58-66.

-5 Brunet A, Sweeney LB, Sturgill JF, Chua KF, Greer PL, Lin Y, Tran H, Ross SE, Mostoslavsky R, Cohen HY, Hu LS, Cheng HL, Jedrychowski MP, Gygi SP, Sinclair DA, Alt FW, Greenberg ME: Stress-dependent regulation of FOXO transcription factors by the SIRT1 deacetylase. Science 2004;303: 011-2015.

6 Leibiger IB, Berggren PO: Sirt1: A metabolic master switch that modulates lifespan. Nat Med 2006;12:3436.

7 Chung S, Yao H, Caito S, Hwang JW, Arunachalam G, Rahman I: Regulation of SIRT1 in cellular functions: Role of polyphenols. Arch Biochem Biophys 2010;501:79-90.

8 Pillai VB, Sundaresan NR, Gupta MP: Regulation of Akt signaling by sirtuins: its implication in cardiac hypertrophy and aging. Circ Res 2014;114:368-378.

-9 Planavila A, Iglesias R, Giralt M, Villarroya F: Sirt1 acts in association with PPAR $\alpha$ to protect the heart from hypertrophy, metabolic dysregulation, and inflammation. Cardiovasc Res 2011;90:276-284.

10 Buitrago-Lopez A, Sanderson J, Johnson L, Warnakula S, Wood A, Di Angelantonio E, Franco OH: Chocolate consumption and cardiometabolic disorders: systematic review and meta-analysis. BMJ 2011;343:d4488.

$\checkmark 11$ Arab L, Liu W, Elashoff D: Green and black tea consumption and risk of stroke: a meta-analysis. Stroke 2009;40:1786-1792.

12 Yang WS, Wang WY, Fan WY, Deng Q Wang X: Tea consumption and risk of type 2 diabetes: a dose-response meta-analysis of cohort studies. Br J Nutr 2014;111:1329-1339.

-13 Schroeter H, Heiss C, Balzer J, Kleinbongard P, Keen CL, Hollenberg NK, Sies H, Kwik-Uribe C, Schmitz HH, Kelm M: (-)-Epicatechin mediates beneficial effects of flavanol-rich cocoa on vascular function in humans. Proc Natl Acad Sci USA 2006;103:1024-1029.

14 Prince PS: (-) Epicatechin prevents alterations in lysosomal glycohydrolases, cathepsins and reduces myocardial infarct size in isoproterenol- inducedmyocardial infarcted rats. Eur J Pharmacol 2013;706:6369.

15 Quine SD, Raqhu PS: Effects of (-)-epicatechin, a flavonoid on lipid peroxidation and antioxidants in streptozotocin induced diabetic liver, kidney and heart. Pharmacol Rep 2005;57:610-615.

-16 Yamazaki KG, Romero-Perez D, Barraza-Hidalgo M, Cruz M, Rivas M, Cortez-Gomez B, Ceballos G, Villarreal F: Short-and long-term effects of (-)-epicatechin on myocardial ischemia reperfusion injury. Am J Physiol Heart Circ Physiol 2008;295:761- 767.

17 Yamazaki KG, Taub PR, Barraza-Hidalgo M, Rivas MM, Zambon CA, Ceballos G, Villarreal FJ: Effects of (-)-epicatechin on myocardial infarct size and left ventricular remodeling after permanent coronary occlusion. J Am Coll Cardiol 2010;55:2869-2876.

- 18 Taub PR, Ramirez-Sanchez I, Ciaraldi TP, Perkins G, Murphy AN, Naviaux R, Hogan M, Maisel AS, Henry RR, Ceballos G, Villarreal F: Alterations in skeletal muscle indicators of mitochondrial structure and biogenesis in patients with type 2 diabetes and heart failure: effects of epicatechin rich cocoa. Clin Transl Sci 2012;5:43-47.

19 De Los Santos S, García-Pérez V, Hernández-Reséndiz S, Palma-Flores C, González-Gutiérrez CJ, Zazueta C, Canto P, Coral-Vázquez RM: (-)-Epicatechin induces physiological cardiac growth by activation of the PI3K/ Akt pathway in mice. Mol Nutr Food Res DOI:10.1002/mnfr.201600343.

20 Ramirez-Sanchez I, Taub PR, Ciaraldi TP, Nogueira L, Coe T, Perkins G, Hogan M, Maisel AS, Henry RR, Ceballos G, Villarreal F: (-)-Epicatechin rich cocoa mediated modulation of oxidative stress regulators in skeletal muscle of heart failure and type 2 diabetes patients. Int J Cardiol 2013;168:3982-3990. 


\section{Cellular Physiology Cell Physiol Biochem 2017;41:2004-2015 \begin{tabular}{l|l} 
and Biochemistry Published & $\begin{array}{l}\text { DOI/1159/000475396 } 2017 \text { The Author(s). Published by S. Karger AG, Basel } \\
\text { www.karger.com/cpb }\end{array}$ \\
\hline
\end{tabular} \\ Published onlıne: April 13, 2017 www.karger.com/cp}

21 Patrucco E, Domes K, Sbroggió M, Blaich A, Schlossmann J, Desch M, Rybalkin SD, Beavo JA, Lukowski R, Hofmann F: Roles of cGMP-dependent protein kinase I (cGKI) and PDE5 in the regulation of Ang II-induced cardiac hypertrophy and fibrosis. Proc Natl Acad Sci USA 2014;111:12925-12929.

-22 Liu L, Wang C, Sun D, Jiang S, Li H, Zhang W, Zhao Y, Xi Y, Shi S, Lu F, Tian Y, Xu C, Wang L: Calhex ${ }_{231}$ Ameliorates Cardiac Hypertrophy by Inhibiting Cellular Autophagy in Vivo and in Vitro. Cell Physiol Biochem 2015;36:1597-1612.

23 Yang J, Zhu HH, Chen GP, Ye Y, Zhao CZ, Mou Y, Hu SJ: Inhibition of farnesyl pyrophosphate synthase attenuates angiotensin II-induced cardiac hypertrophy and fibrosis in vivo. Int J Biochem Cell Biol 2013;45:657-666.

-24 Miyazaki R, Ichiki T, Hashimoto T, Inanaga K, Imayama I, Sadoshima J, Sunagawa K: SIRT1, a Longevity Gene, Downregulates Angiotensin II Type 1 Receptor Expression in Vascular Smooth Muscle Cells. Arterioscler Thromb Vasc Biol 2008;28:1263-1269.

25 Pa J, Gazzaley A: Flavanol-rich food for thought. Nat Neurosci 2014;17:1624-1625.

26 Grassi D, Socci V, Tempesta D, Ferri C, De Gennaro L, Desideri G, Ferrara M: Flavanol-rich chocolate acutely improves arterial function and working memory performance counteracting the effects of sleep deprivation in healthy individuals. J Hypertens 2016;34:1298-1308.

27 Rassaf T, Rammos C, Hendgen-Cotta UB, Heiss C, Kleophas W, Dellanna F, Floege J, Hetzel GR, Kelm M: Vasculoprotective Effects of Dietary Cocoa Flavanols in Patients on Hemodialysis: A Double-Blind, Randomized, Placebo-Controlled Trial. Clin J Am Soc Nephrol 2016;11:108-118.

-28 Jumar A, Schmieder RE: Cocoa Flavanol Cardiovascular Effects Beyond Blood Pressure Reduction. J Clin Hypertens (Greenwich) 2016;18:352-358.

29 Yamazaki KG, Andreyev AY, Ortiz-Vilchis P, Petrosyan S, Divakaruni AS, Wiley SE, De La Fuente C, Perkins G, Ceballos G, Villarreal F, Murphy AN: Intravenous (-)-epicatechin reduces myocardial ischemic injury by protecting mitochondrial function. Int J Cardiol 2014;175:297-306.

- 30 Sheng R, Gu ZL, Xie ML: Epigallocatechin gallate, the major component of polyphenols in green tea, inhibits telomere attrition mediated cardiomyocyte apoptosis in cardiac hypertrophy. Int J Cardiol 2013;162:199209.

-31 Chen DD, Dong YG, Liu D, He JG: Epigallocatechin-3-gallate attenuates cardiac hypertrophy in hypertensive rats in part by modulation of mitogen-activated protein kinase signals. Clin Exp Pharmacol Physiol 2009;36:925-932.

32 Hao J, Kim CH, Ha TS, Ahn HY: Epigallocatechin-3 gallate prevents cardiac hypertrophy induced by pressure overload in rats. J Vet Sci 2007;8:121-129.

-33 Qi HP, Wang Y, Zhang QH, Guo J, Li L, Cao YG, Li SZ, Li XL, Shi MM, Xu W, Li BY, Sun HL: Activation of peroxisome proliferator-activated receptor $\gamma$ (PPAR $\gamma$ ) through NF- $\kappa \mathrm{B} / \mathrm{Brg} 1$ and TGF- $\beta 1$ pathways attenuates cardiac remodeling in pressure-overloaded rat hearts. Cell Physiol Biochem 2015;35:899-912.

-34 Wang RH, He JP, Su ML, Luo J, Xu M, Du XD, Chen HZ, Wang WJ, Wang Y, Zhang N, Zhao BX, Zhao WX, Shan ZG, Han J, Chang C, Wu Q: The orphan receptor TR3 participates in angiotensin II induced cardiac hypertrophy by controlling mTOR signalling. EMBO Mol Med 2013;5:137-148.

- 35 Jiang G, Gong H, Niu Y, Yang C, Wang S, Chen Z, Ye Y, Zhou N, Zhang G, Ge J, Zou Y: Identification of Amino Acid Residues in Angiotensin II Type 1 Receptor Sensing Mechanical Stretch and Function in Cardiomyocyte Hypertrophy. Cell Physiol Biochem 2015;37:105-116.

-36 Kim S, Ohta K, Hamaguchi A, Yukimura T, Miura K, Iwao H: Angiotensin II induces cardiac phenotypic modulation and remodeling in vivo in rats. Hypertension 1995;25:1252-1259.

37 Shen T, Ding L, Ruan Y, Qin W, Lin Y, Xi C, Lu Y, Dou L, Zhu Y, Cao Y, Man Y, Bian Y, Wang S, Xiao C, Li J: SIRT1 Functions as an Important Regulator of Estrogen-Mediated Cardiomyocyte Protection in Angiotensin IIInduced Heart Hypertrophy. Oxid Med Cell Longev DOI:10.1155/2014/713894.

- 38 Oleaga C, Ciudad CJ, Izquierdo-Pulido M, Noé V: Cocoa flavanol metabolites activate HNF-3 $\beta$, SP1, and NFYmediated transcription of apolipoprotein AI in human cells. Mol Nutr Food Res 2013;57:986-995.

-39 Doetzlhofer A, Rotheneder H, Lagger G, Koranda M, Kurtev V, Brosch G, Wintersberger E, Seiser C: Histone deacetylase 1 can repress transcription by binding to Sp1. Mol Cell Biol 1999;19:5504-5511.

-40 Okazaki M, Iwasaki Y, Nishiyama M, Taguchi T, Tsugita M, Nakayama S, Kambayashi M, Hashimoto K, Terada Y: PPAR $\beta / \delta$ regulates the human SIRT1 gene transcription via Sp1. Endocr J 2010;57:403-413. 